\title{
Şekerpancarının (Beta vulgaris L.) Farklı Çeşitlerinde Kalite Kriterleri Üzerine Bir Araştırma
}

\author{
*Amir RAHIMI ${ }^{1}$ Neşet ARSLAN² İsmaeil Rezaei CHIYYANEH ${ }^{1}$ \\ ${ }^{1}$ Urmia Üniversitesi, Ziraat Fakültesi, Tarla Bitkileri Bölümü, Urmia,Iran \\ ${ }^{2}$ Ankara Üniversitesi, Ziraat Fakültesi, Tarla Bitkileri Bölümü, Dışkapı-Ankara \\ *Sorumlu yazar e-posta (Corresponding author e-mail): emir10357@gmail.com
}

\begin{abstract}
Öz
Şekerpancarının (Beta vulgaris L.) rekabet gücünü artırmak amacıyla bir hayli yol alınmıştır. Şeker üretiminde pancarda bulunan şekerin tamamı kristalize edilememektedir. Şekerpancarı kalitesini tanımlayan bazı özellikler arasında şeker dışı maddeler şeker kristalizasyonunu etkiler. Mikro elementler, bitkileri kalite ve verim açısından etkilemektedir. Bu denemede kullanılan mikro elementlerin ( $\mathrm{Fe}, \mathrm{Zn}, \mathrm{B}$ ve $\mathrm{Mn}$ ), şekerpancarında kalite kriterleri üzerine olan etkisi araştırılmıştır. Bu araştırma 2005-2006 yıllarında İran'ın şekerpancarı açısından önemli bölgelerinden biri olan Batı Azerbaycan'ın Sulduz bölgesinde bulunan şekerpancarı fabrikasında gerçekleştirilmiştir. Araştırma tesadüf blokları deneme desenine göre, 4 tekerrürlü olarak kurulmuştur. Örneklerdeki şeker oranı, Na, K ve N miktarları Betalyser Sistemi (Sucromat otomatik sakkarimetre, alev fotometre ve testamin fotometre) kullanılarak analiz edilmiştir. Bu sonuçlardan bilgisayar programı yardımıyla kristalize edilebilen şeker miktarı, alkalinite ve melastaki şeker oranı belirlenmiştir. Elde edilen bulgulara göre; şeker oranı \%15.48-17.77, K varlığı 6.65-7.86 (meq/100 g pulp), Na varlığı 1.30-1.95 (meq/100 g pulp), N varlığı 1.34-7.95 (meq/100 g pulp), alkalinite 3.12-7.95, kristalize edilebilen şeker oranı \%12.32-13.81, şeker randımanı \%77.72-79.59 ve melastaki şeker oranı \%3.25-3.95 arasında değişmiştir.
\end{abstract}

Anahtar Kelimeler: Alkalinite, Sulduz, şekerpancarı, şeker randımanı, çeşit

\section{A Research on Quality Criteria in Different Cultivars of Sugar Beet (Beta vulgaris L.)}

\section{Abstract}

In order to increase sugarbeet competitiveness it is necessarry to consider many things. It is not possible to crystalyze all sugar in sugarbeet. Some characteristics of sugarbeet that determine the quality are nonsugar substances. The aim of the study was to find the effects of different sugarbeet cultivars on the quality of the plant. the study was carried out during 2005-2006 at the agricultural lands of Sulduz region (most important region in terms of sugarbeet production), West Azerbaycan Province, Iran, affiliated to the Sugarbeet Factory of the region. The sugar percentage and the amounts of $\mathrm{Na}, \mathrm{K}$ and $\mathrm{N}$ were analysed by Betalyser System (Sucromat automatic Saccharometer, flame photometer and testamin photometer). Crystallized sugar percentage, alkalinity, the precentage of sugar in molasses and sugar yield were also determined. The findings showed that sugar percentage, amount of $\mathrm{K}, \mathrm{Na}, \mathrm{N}$, alkalinity, crystallized sugar percentage, sugar yield and percentage of sugar in molasses were between $\% 14.88-19.21, \% 3.71-5.05$ (meq/100 g pulp), 1.43.73 (meq/100 g pulp), 1.91-2.89 (meq/100 g pulp), 2.48-7.35, \%11.63-16.53, \%78.08-87.85 and \%2.28-3.25 respectively.

Keywords: Alkalinity, Sulduz, sugar beet, sugar yield, cultivar

\section{Giriş}

nsan ve evcil hayvanların besin maddeleri tarım sektöründen elde edilmektedir. Hammadde olarak tarımsal ürünlerin yerini alabilecek bir alternatif söz konusu değildir (Bayramoğlu 2010 ). Şekerin üretim tarihi çok eskilere gitmektedir. Şekerpancarı tarımı,

sağladığı yüksek katma değer, yan ürünlerin hayvan yemi olma ve tarımda sağladığı istihdam özelliği dolayısıyla çok önemli bir bitkidir (Günel ve ark. 2005). Dünyada, 120 ülkede yaklaşık olarak 148 milyon ton şeker üretilmektedir. Üretilen şekerin aşağı yukarı \%20'si 
şekerpancarından, \%80'i ise şekerkamışından gerçekleştirilmiştir. Ekonomik rekabetin sektörel genişlik kazanması ve her hangi bir uluslararası kazaya kurban gitmemek için rekabeti denetlemekte aktif olmak isteyen uluslar, sistemin ana unsurlarından biri olan tarım ürünlerini çeşitli enstrümanlar kullanarak kontrol etmek istemektedirler (Günel ve ark. 2010). İstatistik verilere göre İran'da 2013-2014 ziraii yılında 107.000 ha alanda şekerpancarı ekilmiş, hektara ortalama verimi $39.200 \mathrm{~kg}$ ve toplam şekerpancarı üretimi ise 4.185.000 ton olmuştur. Aynı yılda kişi başına şeker tüketimi ise 33.70 kg/yılda olmuştur (Anonim 2014). Şekerin, ilk kez ne zaman ve kim tarafından kullanıldığı bilinmemekle beraber yapılan çalışmalar, Kuzey Hindistan'da Gange Nehri civarından elde edildiğini doğrulamaktadır (Baykut, 1958). Ekolojik şartları şekerpancarı üretimine elverişli olması ve İran'ın Batı Azerbaycan ilinin Sulduz (Naghadeh) ilçesinde (36:57 E , 45:22 N) şekerpancarı fabrikası bulunması nedeniyle, şekerpancarı bitkisel üretim açısından bu yöre ve çevresinde en önde gelen ürünlerden biridir. Nüfusun büyük bir kısmı tarımla uğraşır. Azeri Türkçesinde Sulduz kelimesinin anlamı sulu ve düz demektir (Aghaalinejad 2011).

Şekerpancarı içerdiği şeker itibarı ile yüksek enerji ve saf besin kaynağı olarak insanlar için hayati önem taşımaktadır (Oral, 1979). Şekerpancarında şeker varlığı ve Şeker dışı maddeler ( $\alpha$-amino $\mathrm{N}, \mathrm{Na}, \mathrm{K}$, invert şeker, dekstran, rafinoz vs.) şekerpancarı kalitesini tanımlayan bazı özellikler içerisinde yer almaktadır. Şeker dışı maddeler şeker kristalizasyonunu düşürerek şekerpancarını nitel biçimde olumsuz yönde etkiler; dolayısıyla şeker üretiminde pancarda bulunan şekerin tamamı kristalize edilememektedir (Vukov 1971). Şeker dışı maddelerin verileri, kristalize edilebilen şeker oranını belirlemek için birçok formülde yer almaktadır (Sheykhuleslami 1996). Şekerpancarında adı geçen elementlerin bulunması kristalizasyon aşamasında bir engel oluşturur ve daha fazla şekeri melasa doğru götürür (Hilde and et al. 1983) ve bu yüzden şeker randımanı tarladaki üretilen şekerpancarına bağlıdır (Alexander 1971). Çeşitli faktörler, şekerpancarı kalitesini etkilemektedir; örneğin Vokov (1977) şekerpancarında kaliteyi etkileyen 28 faktörün etkili olduğunu kaydetmiştir. Bitkisel üretimde verim ve kaliteyi doğrudan etkileyen faktörlerden bir tanesi tohumluktur. Tohum çeşidi şekerpancarı üretiminde de verim ve kaliteyi etkileyen en önemli faktörlerden biridir.
Bir ülkede tarımın yönü ve seviyesi o ülkede kaliteli tohumlukların çiftçiler tarafından temin edilip kullanılma derecesi ile çok yakından ilişkilidir. Islah edilmiş kaliteli tohumlukların tarımda kullanılması hem tarımsal işletmeler hem de bölgesel ve ülkesel ekonomiler açısından kayda değer faydalar temin etmektedir. Tarımda genetik potansiyeli düşük bitki çeşitleri ve kalitesiz tohumlukların kullanılması halinde, çoğu zaman diğer girdilerden beklenen yararları gerçekleştirmek mümkün değildir (Akyol ve Arda 1942).

İran'ın şekerpancarı üretim bölgelerınde, son yıllarda şekerpancarı tarımında tohumluk seçiminde çiftçilere esneklik sağlanmış, çifçiler fabrikaların verdiği tohumun yanı sıra piyasadan temin ettiği farklı şekerpancarı tohumlukları kullanmaya başlamışlardır. İran'da şekerpancarı fabrikalarca çiftçilere verilen para, pancar ağırığı ve şeker oranına göredir; bu yüzden çiftçilere, pancar verimi yanı sıra şeker oranı da önemlidir. Son zamanlarda fabrikalarca, kristalize edilebilen şeker oranı gibi, diğer kalite kriterleri uygulama politikası da düşünülmektedir; dolayısıyla çifçiler kalite bakımından en üst düzeyde olan çeşitlere yönelmesinde fayda vardır. Şeker fabrikaları açısından konuya bakıldığında, verilen ham madde, nitel biçimde kaliteliyse, artırıcı bir etmen olarak, şeker sanayinin ilerlemesine yardımcı olacaktır. Çifçiler son yıllarda piyasada çok sayıda çeşidin olması nedeniyle bilinçsiz çok yüksek fiyatlarla tohum almaktadır. Çeşit seçilirken dikkat edilmesi gereken önemli özelliklerden ekilen yörenin iklim ve toprak yapısına uygun olmasıdır. Bu araştırmada, yöredeki bulunan veya fabrikalarca çiftçiye verilen şekerpancarı çeşitleri kalite açısından kiyaslanmıştır. Yapılan bu araştırma sonocu bölgedeki çiftçilere kaliteli ve maliyeti düşük tohumlar sunulabilecek.

\section{Materyal ve Yöntem}

Bu araştırma, 2005-2006 yıllarında İran'ın şekerpancarı açısından önemli bölgelerinden biri olan Batı Azerbaycan ilinin Sulduz yöresindeki bir tarlada yapılmıştır. Bu yöre Urmiye gölü, Urmiye, Mahabad, Miyandab ve Piranşehr şehirleri, Türkiye ve Irak ülkelerince sınırlanmıştır. Yörenin yüksekliği 1000-2100 m arasında değişmektedir. Drenajı iyi olan topraklarının derinliği yarı derin ve derin arasında, toprak tekstürü ise orta ve ağır topraklar gurubu arasındadır. Meteoroloji verilerine göre yıllık ortalama sıcaklık 11.3$13.71^{\circ} \mathrm{C}$ arasındadır. Yaz ortalama sıcaklığı $22.76^{\circ} \mathrm{C}$ ve kış ortalama sıcaklığı $2.45^{\circ} \mathrm{C}$, en 
soğuk aylar Aralık-Ocak $\left(-0.3^{\circ} \mathrm{C}\right)$, en sıcak aylar Temmuz- Ağustos $\left(24.21^{\circ} \mathrm{C}\right)$ ve ortalama yağış miktarı ise $326.43 \mathrm{~mm}$ dir. Sulu tarımda kullanılan tarlaların eğimi $2-5^{\circ} \mathrm{C}$ arasında değişmektedir (Aghaalinejad 2011).

Toprak örnekleri tarlayı temsil edecek şekilde 0-30 cm toprak derinliğinden alınmıştır. Alınan toprak örnekleri havada kuru hale geldikten sonra, 2 mm'lik elekten geçirilerek analizler için hazırlanmıştır. Toprak örneği Sulduz Toprak Analiz Laboratuarı'na gönderilmiştir. Analiz sonuçları çizelge 1 'de gösterilmektedir.

Çizelge1. Deneme yerinin toprak analiz sonuçları Table 1. Soil analysis of experiment area

\begin{tabular}{ll}
\hline $\mathrm{P}_{2} \mathrm{O}_{5}(\mathrm{~kg} / \mathrm{da})$ & 11.0 \\
$\mathrm{~K}_{2} \mathrm{O}(\mathrm{kg} / \mathrm{da})$ & 173 \\
Organik Madde (\%) & 1.25 \\
Toplam Azot (\%) & 0.10 \\
$\mathrm{TNV}(\%)$ & 7.8 \\
$\mathrm{SP}(\%)$ & 42 \\
$\mathrm{EC}(\mathrm{dS} / \mathrm{m})$ & 0.791 \\
$\mathrm{Kil}(\%)$ & 24 \\
$\mathrm{~T}$ In $(\%)$ & 46 \\
$\mathrm{Kum}(\%)$ & 30 \\
$\mathrm{Ph}$ & 7.93 \\
\hline
\end{tabular}

Araştırma tesadüf blokları deneme desenine göre 4 tekerrürlü olarak kurulmuştur. Araştırmada Rasul, Zargan, Sonja, Şirin, Flores, Laetitia ve Univers çeşitleri kullanılmıştır. Tohumların ekimi sıra arası $50 \mathrm{~cm}$ ve her parselde 6 sıra olacak şeklinde el markörü ile işaretlenen çizgilere 12.04.2006 tarihinde yapılmıştır. Ekim zamanında çıkış açısından, yağış ve toprak nemi uygun durumda olmuştur. Fosfor ve Potas gübrelerinin 2/3'ü sonbaharda sürümde taban gübresi olarak pulluk altına, 1/3 'ü ise ilkbaharda tohum yatağı hazırlığında azot gübresi ile beraber verilmiştir. Öngörülen azotun yarısı tohum yatağı hazırlamadan önce tırmık altına, diğer yarısı da baş gübresi olarak en geç son ot çapası altına verilmiştir. Toprak Analiz Laboratuarın tavsiyesine uyarak $20 \mathrm{~kg}$ da- 1 saf $\mathrm{N}$ ve $8 \mathrm{~kg}$ da-1 saf $\mathrm{P}_{2} \mathrm{O}_{5}$ ve $6 \mathrm{~kg}$ da- 1 saf $\mathrm{K}_{2} \mathrm{O}$ gübre hesabıyla, tüm parsellerde kullanılmıştır. Çıkışlardan sonra yabancı otlara karşı kimyasal mücadele yapılmıştır. Bitkiler ekim zamanlarına göre 2-4 yapraklı döneme eriştikten sonra sıra üzeri ortalama $20 \mathrm{~cm}$ olacak şekilde seyreltme işlemine tabi tutulmuştur. Yabancı ot yoğunluğu dikkate alınarak, pancar yaprağı toprağı örtünceye kadar çapa işlemine devam edilmiştir. Toplam 4 kez çapalama yapılmış ve bu işlem genellikle sulamadan sonra yapılarak yabancı otların gelişimi engellenmiş ve kaymak tabakasının kırılması sağlanmıştır. Pancar bitkisinin gelişme dönemi boyunca topraktaki nem durumu dikkate alınarak $7 \mathrm{kez}$ olmak üzere yağmurlama sulama işlemi uygulanmıştır. Ağustos ayının başlarında şeker pancarında görülen yaprak bitine karşı sistemik ilaç kullanılarak mücadele yapılmıştır. Ayrıca ağustos ayının ortalarına doğru külleme hastalığına rastlanmıştır. Bu nedenle 5 Ağustos olmak üzere bir kez ilaçlama yapılarak hastalık kontrol altına alınmıştır. Bitkilerin hasadı 26 Ekim 2006 tarihinde yapılmıştır. Araştırmada; şeker oranı, $\mathrm{Na}, \mathrm{K}$ ve $\mathrm{N}$ miktarları, kristalize edilebilen şeker oranı, alkalinite ve melastaki şeker oranı özellikleri ele alınmıştır. Alınan pancar numuneleri özenle yıkanıp veenema cihazı ile pulplar (hamur) hazırlanmıştır. Hazırlanan pulp numuneleri kapaklı özel kaplara yerleştirilip, kimyevi analizlerin yapılmasına dek dip frizde $\left(-20^{\circ} \mathrm{C}\right)$ bekletilmiştir. Kimyevi analizler İsfahan şekerpancarı fabrikalarının ortak araştırma laboratuarında gerçekleştirilmiştir. Numuneler laboratuar sıcaklığında (yaklaşık $20^{\circ} \mathrm{C}$ ) donu açılana kadar bekletilmiş ve 26 gram pulp numunesi kimyevi analizler için kullanılmıştır. Hazırlanmış çözelti Betalyser Sistemi (Sucromat otomatik sakkarimetre, alev fotometre ve testamin fotometre)'ne konarak, numunedeki şeker oranı, $\mathrm{Na}, \mathrm{K}$ ve $\mathrm{N}$ varlığı belirtilmiştir. Bu verileri kullanarak numunelerin alkalinitesi, Melastaki şeker oranı-Molasses sugar (MS), kristalize edilebilen şeker oranı-White sugar content (WSC) ve şeker randımanı-Extraction coefficient of sugar (ECS) hesaplanmıştır (Sohrabi et al. 2006). Özelliklerin hepsinde EXEL programı kullanarak ortalama hesaplanmış ve eğimler çizilmiştir.

\section{Bulgular ve Tartışma}

\section{Şeker Oranı (\%)}

Elde edilen bulgulara göre, farklı çeşitlerden alınan şekerpancarı numunelerinin ortalama şeker oranı \% 15.17-19.21 arasında değişmiştir; en yüksek oran Şirin çeşidine ve en düşük oran Rasul çeşidine aittir (Çizelge 2.). Ilkaii et al. (2012) gerçekleştirdikleri iki yıllık bir denemde 14 çeşidi, verim ve kalite bakımından kıyaslamışlardır. Bu araştırmanın sonucuna göre şeker oranı \%13.0-14.60 arasında değişmiş ve çeşitler arasındaki farklılık anlamlı $(p<0.01)$ çıkmıştır. Rahimi ve Arslan (2012), yaptıkları bir denemde, şekerpancarı kalitesi üzerine rakımın etkisini araştırmışlardır; bulgularına göre, şeker oranı \%16.16-18.45 arasında değişmiştir. Mirzaei and 
Ghadamifiruzabadi (2007) İran'ın Hamadan ilinde iki yıl süreyle yürüttükleri bir sulama denemesinde, ortalama şeker oranını \%16.1918.87 arasında bulmuşlardır. Nourju and Baghayikiya (2004) tarafından İran'ın Batı Azarbaycan ilinin Khoy ilçesinde yapılan bir araştırma sonucuna göre, ortalama şeker oranı \%12.74-16.09 arasında bulunmuştur.

\section{K Varlığı (meq/100 g pulp)}

Elde edilen bulgulara göre, farklı çeşitlerden alınan şekerpancarı numunelerinin ortalama $\mathrm{K}$ varlığı 3.71-5.30 (meq/100 g pulp) arasında değişmiş, en düşük ve en yüksek varlık sırasıyla Flores ve Rasul'de bulunmuştur (Çizelge 2.). Rahimi ve Arslan (2012)'ın bulgularına göre, farklı rakımlarda K varlığı 3.95-5.23 (meq/100 g pulp) arasında değişmiştir. Mirzaei and Ghadamifiruzabadi (2007) İran'ın Hamadan ilinde yürüttükleri bir sulama denemesinde, ortalama K varlığını 4.42-5.81 (meq/100 g pulp) arasında kaydetmişlerdir. Ilkaii et al. (2012) sonuçlarına göre K varlığı 6.1-6.7 (meq/100 g pulp) arasında değişmiş ve çeşitler arasındaki farklılık anlamlı $(p<0.05)$ çıkmıştır. Nourju and Baghayikiya (2004) tarafından İran'ın Batı Azarbaycan ilinin Khoy ilçesinde yapılan bir araştırma sonucuna göre, ortalama $\mathrm{K}$ varlığı 6.06-6.88 (meq/100 g pulp) arasında kaydedilmiştir.

\section{Na Varlığı (meq/100 g pulp)}

$\mathrm{Bu}$ araştırmanın sonuçlarına göre farklı çeşitlerden alınan şekerpancarı numunelerinin ortalama Na varlığı 1.40-2.69 (meq/100 g pulp) arasında değişmiş, en düşük ve en yüksek varlık sırasıyla Laetitia ve Flores'te bulunmuştur (Çizelge 2.). Ilkaii ve ark. (2012) sonuçlarına göre $\mathrm{Na}$ varlığı 1.4-2.2 (meq/100 g pulp) arasında değişmiş ve çeşitler arasındaki farklıık anlamlı $(p<0.01)$ çıkmıştır. Rahimi ve Arslan (2012)'ın bulgularına göre, farklı rakımlard $\mathrm{Na}$ varlığı 1.27-2.94 (meq/100 g pulp) arasında değişmiştir. Mirzaei and Ghadamifiruzabadi (2007) İran'ın Hamadan ilinde yürüttükleri bir sulama denemesinde, ortalama $\mathrm{Na}$ varlığını 1.00-1.65 (meq/100 g pulp) arasında bulmuşlardır. Nourju and Baghayikiya (2004) tarafından İran'ın Batı Azarbaycan ilinin Khoy ilçesinde yapılan bir araştırma sonucuna göre, ortalama Na varlığı 2.88-4.81 (meq/100 g pulp) arasında kaydedilmiştir.

\section{N Varlığı (meq/100 g pulp)}

Edinilen bulgulara göre farklı çeşitlerden alınan şekerpancarı numunelerinin ortalama $\mathrm{N}$ varlığı 1.91-3.46 (meq/100 g pulp) arasında değişmiş, en düşük ve en yüksek varlık sırasıyla Şirin ve Rasul'de görünmüştür (Çizelge 2.). Rahimi ve Arslan (2012)'ın bulgularına göre, farklı rakımlarda N varlığı .43-3.44 (meq/100 g pulp) arasında değişmiştir. Mirzaei and Ghadamifiruzabadi (2007) İran'ın Hamadan ilinde yürüttükleri bir sulama denemesinde, ortalama N varlığını 0.82-2.99 (meq/100 g pulp) arasında kaydetmişlerdir. Nourju and Baghayikiya (2004) tarafından İran'ın Batı Azarbaycan ilinin Khoy ilçesinde yapılan bir araştırma sonucuna göre, ortalama $\mathrm{N}$ varlığı 4.95-6.62 (meq/100 g pulp) arasında gösterilmiştir.

Çizelge 2. Şeker Oranı\% (I) , K(II), Na(III) ve N(IV) Varlığı (meq/100g pulp), Alkalinite\%(V), Kristalize Edilebilen Şeker Oranı\%(VI), Şeker Randımanı\%(VII) ve Melasın Şeker Oranı\%(VIII)

Table 2. Sugar percentage \% (I), K (II), Na (III) and N (IV) Content (meq/100g pulp), Alkalinity \% (V), Crystallized sugar percentage \% (VI), Sugar Yield \% (VII) and Percentage of Sugar in Molasses \% (VIII)

\begin{tabular}{ccccccccc}
\hline & $\mathrm{I}$ & $\mathrm{II}$ & $\mathrm{III}$ & $\mathrm{IV}$ & $\mathrm{V}$ & $\mathrm{VI}$ & $\mathrm{VII}$ & VIII \\
\hline \multirow{2}{*}{ Rasul } & 15.17 & 5.30 & 1.925 & 3.46 & 2.11 & 11.87 & 80.00 & 3.2 \\
& \pm 0.25 & \pm 0.08 & \pm 0.09 & \pm 0.13 & \pm 0.10 & \pm 0.45 & \pm 0.13 & \pm 0.08 \\
Zargan & 16.98 & 4.66 & 2.44 & 2.89 & 2.81 & 13.98 & 82.32 & 3.00 \\
& \pm 1.41 & \pm 0.45 & \pm 1.13 & \pm 1.19 & \pm 1.48 & \pm 1.32 & \pm 2.63 & \pm 0.48 \\
Sonja & 18.97 & 4.29 & 1.82 & 2.07 & 2.86 & 16.34 & 86.61 & 2.57 \\
& \pm 0.10 & \pm 0.04 & \pm 0.06 & \pm 0.05 & \pm 0.04 & \pm 0.13 & \pm 0.31 & \pm 0.04 \\
Şirin & 19.21 & 5.05 & 2.09 & 1.91 & 3.75 & 16.29 & 84.78 & 2.92 \\
Flores & \pm 0.42 & \pm 0.68 & \pm 0.17 & \pm 0.10 & \pm 0.07 & \pm 0.60 & \pm 1.29 & \pm 0.18 \\
& 16.32 & 3.71 & 2.69 & 2.62 & 2.48 & 13.59 & 83.16 & 2.74 \\
Laetitia & \pm 1.32 & \pm 0.12 & \pm 0.18 & \pm 0.28 & \pm 0.29 & \pm 1.31 & \pm 1.32 & \pm 0.01 \\
& 18.82 & 3.87 & 1.40 & 1.98 & 3.05 & 16.54 & 87.85 & 2.28 \\
Universe & \pm 0.21 & \pm 0.32 & \pm 0.23 & \pm 0.80 & \pm 0.96 & \pm 0.47 & \pm 1.54 & \pm 0.27 \\
& 16.79 & 4.51 & 2.56 & 2.11 & 3.35 & 13.87 & 82.72 & 2.92 \\
\hline
\end{tabular}




\section{Alkalinite}

Elde edilen bulgulara göre, farklı çeşitlerden alınan şekerpancarı numunelerinin ortalama alkalinite 2.11-3.75 arasında değişmiş, en düşük ve en yüksek sırasıyla Şirin ve Rasul'de bulunmuştur (Çizelge 2.). Nourju and Baghayikiya (2004) tarafından İran'ın Batı Azarbaycan ilinin Khoy ilçesinde yapılan bir araştırma sonucuna göre, ortalama alkalinite oranı 2.22-4.52 (\%) arasında kaydedilmiştir. Mirzaei and Ghadamifiruzabadi (2007) İran'ın Hamadan ilinde yürüttükleri bir sulama denemesinde, ortalama alkalinite oranını \%2.33-7.92 arasında kaydetmişlerdir. Rahimi ve Arslan (2012)'ın bulgularına göre, farklı rakımlarda alkalinite 2.53-4.47arasında değişmiştir.

\section{Kristalize Edilebilen Şeker Oranı (\%)}

$\mathrm{Bu}$ araştırmanın sonuçlarına göre farklı çeşitlerden alınan şekerpancarı numunelerinin ortalama Kristalize edilebilen şeker oranı \%11.87-16.54 arasında değişmiş, en yüksek ve en düşük oran sırasıyla Laetitia ve Rasl'de bulunmuştur (Çizelge 2.). Rahimi ve Arslan (2012)'ın bulgularına göre, farklı rakımlarda Kristalize edilebilen şeker oranı \%12.99-15.77 arasında değişmiştir. Mirzaei and Ghadamifiruzabadi (2007) İran'ın Hamadan ilinde yürüttükleri bir sulama denemesinde, ortalama Kristalize edilebilen şeker oranını 14.10-16.63 (\%) arasında kaydetmişlerdir. Çamaş ve ark. (2007) iki yıl süre içerisinde Türkiye'nin 5 farklı bölgesinde yürüttükleri bir denemede, Kristalize edilebilir şeker oranını 10.79-13.12 arasında kaydedilmiştir. Nourju and Baghayikiya (2004) tarafından İran'ın Batı Azarbaycan ilinin Khoy ilçesinde yapılan bir araştırma sonucuna göre, ortalama kristalize edilebilen şeker oranı \%9.05-12.43 arasında bulunmuştur.

\section{Şeker Randımanı (\%)}

Edinilen bulgulara göre farklı çeşitlerden alınan şekerpancarı numunelerinin ortalama şeker randımanı 80.00-87.85 arasında değişmiş, en yüksek ve en düşük şeker randımanı sırasıyla Laetitia ve Rasul'de görünmüştür (Çizelge 2.). Çamaş ve ark. (2007) iki yıl süre içerisinde Türkiye'nin 5 farklı bölgesinde yürüttükleri bir denemede, ortalama şeker randımanı 84.14-89.33 arasında bulmuşlardır. Mirzaei and Ghadamifiruzabadi (2007) İran'ın Hamadan ilinde yürüttükleri bir sulama denemesinde, ortalama şeker randımanını 86.68-90.75 (\%) arasında bulmuşlardır. Nourju and Baghayikiya (2004) tarafından İran'ın Batı Azarbaycan ilinin Khoy ilçesinde yapılan bir araştırma sonucuna göre, ortalama şeker randımanı \%2.88-4.81 arasında kaydedilmiştir. Rahimi ve Arslan (2012)'ın bulgularına göre, farklı rakımlarda şeker randımanı \%79.31-84.55 arasında değişmiştir.

\section{Melastaki Şeker Oranı (\%)}

Elde edilen bulgulara göre, farklı çeşitlerden alınan şekerpancarı numunelerinin ortalama melastaki şeker oranı \%2.28-3.20 arasında değişmiş, en düşük ve en yüksek sırasıyla Rasul ve Laetitia'da bulunmuştur (Çizelge 2.). Rahimi ve Arslan (2012)'ın bulgularına göre, farklı rakımlarda melastaki şeker oranı \%2.703.28 arasında değişmiştir. Abdel-Motagally and Attıa (2009) iki yıllık bir denemede şekerpancarı üzerine potasyum ve nitrojen gübrelerini uygulamışlardır. Bu denemenin sonuçlarına göre, ortalama melastaki şeker oranı 2.80-3.19 arasında bulmuşlardır. Mirzaei and Ghadamifiruzabadi (2007) İran'ın Hamadan ilinde yürüttükleri bir sulama denemesinde, ortalama melastaki şeker oranını 1.68-2.39 (\%) arasında kaydetmişlerdir. Nourju ve Baghayikiya (2004) tarafından İran'ın Batı Azarbaycan ilinin Khoy ilçesinde yapılan bir araştırma sonucuna göre, ortalama melastaki şeker oranı 2.88-4.81 (meq/100 g pulp) arasında kaydedilmiştir.

\section{Sonuç}

Elde edilen sonuçlara göre; şeker oranı \%14.88-19.21, K miktarı 3.71-5.05 mg/l, görünmüştür. $\quad \mathrm{Na}$ miktarı 1.4-3.73 mg/l, N miktarı 1.91-2.89 mg/l, alkalinite 2.48-7.35, kristalize edilebilen şeker oranı \%11.63-16.53, şeker randımanı \%78.08-87.85 ve melastaki şeker oranı \%2.28-3.25 arasında değişmiştir.

\section{Kaynaklar}

Abdel-Motagally F.M.F., Attia K.K., 2009. Response of sugar beet plants to nitrogen and potassium fertilization in sandy calcareous soil. Int. J. Agric. Biol., 11 (6): 695-700

Aghaalinejad M., 2011. Florsitic Evaluation of Plant Diversity in Naghadeh (Sulduz). A thesis in biology branch, Marand Islamic University. Marand, Iran. (Farsça)

Akyol H., ve Arda M., 1942. Genel coğrafya. Maarif matbaası, İstanbul 
Alexander J.T., 1971. Factors affecting quality.P: 371381. In Johnson RT, Alexander JT, Rush GE, Hawkes GR(eds). Advances in sugar beet production; Principles and practices. The lowa State Univ. Press. Ames.IA

Anonim 2014. http://www.pankobirlik.com.tr (Erişim tarihi: 07.07.2015)

Baykut N., 1958. Dünya ve memleketimizde şeker sanayinin doğuşu ve erzurum şeker fabrikasının bölge üzerindeki iktisadî ve sosyal tesirleri. Şeker, 3(36): 3; T. Veldet. 30. Yılında Türkiye Şeker Sanayi, Ankara, 4-6

Bayramoğlu Z., 2010.Tarımsal verimlilik ve önemi. Selçuk Tarım ve Gıda Bilimleri Dergisi, 24 (3): 52-61

Çamaş N., Çırak C. and Albayrak S., 2007. Yield and quality of sugarbeet growen under northern Turkey condition. Int. J. of Agricultural Reserch, 2(3): 296-301

Günel E., Çalışkan M.E., Tortopoğlu A.I.., Kuşman N., Tuğrul K.M., Yılmaz A., Dede Ö. ve Öztürk M., 2005. Nişasta ve Şeker Bitkileri Üretimi. Türkiye Ziraat Mühendisliği VI. Teknik Kongresi Bildiri Kitabı, 431-457, Ankara

Hilde D.J., Bass S.R., Levos S., Ellingson R.L., 1983. Grower practices system promotes beet quality improvment in the Red River Valley. J. Am. Soc. Sugar beet Technol., 22: 73-88

Ilkaii M.N., Habibi D., Fruzesh P., Fathollah Taleghani D., Rajabi A., Orujnia S. and Fard Davudi M., 2012. Investigation of quality and quantity properties in different sugar beet genotypes under drought stress, Tarım ve Islah Dergisi, 8(4): 101-111. (Farsça)
Nourju A., Baghayikiya M., 2004. Study on the irrigation scheduling effects in different growth stages on quantity and quality of sugarbeet in Khoy region, İran. J. of Sugarbeet.20(1): 2738. (Farsça)

Oral E., 1979. Nişasta ve Şekerli Bitki Yetiştiriciliği Tekniği. Atatürk Üniversitesi Ziraat Fak. Yayınları

Rahimi A. ve Arslan N., 2012. Farklı Rakımlarda Yetiştirilen Şekerpancarlarının (Beta vulgaris L.) Kalite Yönünden Karşılaştırılması . 1. Uluslararası anadolu şeker pancarı sempozyumu, Kayseri, Türkiye, 136-142

Sohrabi Y. and et al., 2006. Investigation of limited irrigation and root harvesting dates on yield and some of quality charactrestices of sugarbeet. J. of Pajouhesh and Sazandeghi. 70: $8-15$

Sheykholeslami R., 1996. Şeker üretimi ve şekerpancarında kaliteyi tanımlamak için formüllerin daha kullanışlı yapmak, Şekerpancarı bilimsel dergisi, 1-2: 72. (Farsça)

Vokov K., 1977. Physices and chemistry of sugarbeet in sugar manufacture. Elsever. Amesterdam: 595

Vukov K., 1971. Şekerpancarının fizik ve kimyası. T.Ş.F.A.Ş., Yayınları: 208: 97, Ankara 